\title{
APRENDIZAGEM COLABORATIVA NO ENSINO DE HISTÓRIA: A SALA DE AULA INVERTIDA COMO METODOLOGIA ATIVA
}

Lyslley Ferreira dos Santos - UNESP-Bauru - lyslleysantos@ gmail.com

Thaís Cristina Rodrigues Tezani - UNESP-Bauru - thais.tezani@unesp.br

\section{RESUMO}

Com o advento das Tecnologias Digitais da Informação e Comunicação (TDIC), vivenciamos a necessidade da utilização de metodologias ativas nas práticas pedagógicas dos docentes, sendo uma possibilidade, a Sala de Aula Invertida que, aliada ao uso das TDIC, pode contribuir nesse processo. Esta pesquisa buscou aplicar a referida metodologia nas aulas de História e analisar seus desafios e potencialidades como possibilidade para o processo de ensino e aprendizagem pautado na colaboração em uma sala do $2^{\circ}$ ano do Ensino Médio de uma escola pública estadual do interior do Estado de São Paulo. A metodologia de abordagem qualitativa seguiu caminhos teóricos, empíricos e os resultados poderão auxiliar os professores a repensar e inovar suas práticas em sala de aula.

Palavras-chave: Sala de Aula Invertida. Tecnologias Digitais da Informação e Comunicação. História.

\section{COLLABORATIVE LEARNING IN THE TEACHING OF HISTORY: THE CLASSROOM INVERTED AS AN ACTIVE METHODOLOGY}

\begin{abstract}
With the advent of the Digital Information and Communication Technologies (TDIC), we have experienced the need to use active methodologies in the pedagogical practices of the teachers, and it is possible that the Inverted Classroom, combined with the use of TDICs, can contribute to this process. This research sought to apply said methodology in History classes and analyze their challenges and potentialities as a possibility for the process of teaching and learning based on collaboration in a room of the second year of High School of a state public school in the interior of the State of São Paulo. The methodology of qualitative approach followed theoretical, empirical ways and the results could help teachers to rethink and innovate their practices in the classroom.
\end{abstract}

Keywords: Inverted Classroom. Digital Information and Communication Technologies. Story.

\section{INTRODUÇÃO}

Este artigo apresenta parte dos resultados de uma dissertação de Mestrado Profissional do Programa de Pós-Graduação em Docência para Educação Básica, realizado pela pesquisadora, na Faculdade de Ciências, UNESP de Bauru-SP, que analisou os desafios e possibilidades da utilização da metodologia Sala de Aula Invertida no Processo de Ensino e Aprendizagem de História em articulação com as Tecnologias Digitais da Informação e Comunicação (TDIC) e a necessidade de realizar novos encaminhamentos pedagógicos frente aos alunos contemporâneos.

Ao constatar o desinteresse dos alunos do Ensino Médio que vivenciam a tecnologia fora dos muros da escola e a prática dos professores que pouco utilizam o universo digital, frente a esse cenário, observações e questionamentos vivenciados 
durante a prática docente da pesquisadora, surgiu a necessidade de realização da pesquisa citada.

Durante os horários de intervalo e Aula de Trabalho Pedagógico Coletivo (ATPC), eram constantes os relatos e as queixas dos professores quanto à falta de interesse, ao descomprometimento, à indisciplina e à desmotivação dos alunos com as atividades propostas nas aulas das diversas disciplinas do Ensino Médio, comprometendo o processo de ensino e aprendizagem e, dificultando também a avaliação da aprendizagem pelo professor.

\section{CONSIDERAÇÕES TEÓRICAS: A SALA DE AULA INVERTIDA COMO METODOLOGIA ATIVA}

Para Palfrey e Gasser (2011) e Tezani (2011), os alunos de hoje estão processando informações e aprendendo de maneira diferente, sendo necessária a compreensão desse fato por parte dos educadores e uma mudança nas estruturas educacionais, contudo, mesmo com o universo das TDIC, estes ainda continuam presos à sala de aula da era industrial, ou seja, tradicional, enquanto os alunos vivem na era tecnológica fora dos muros da escola.

Diante do exposto, acreditamos que o aluno necessite de um atendimento que desperte e mantenha seu interesse pela escola e que o ajude a se desenvolver de acordo com suas necessidades. Diversas estratégias didáticas devem ser utilizadas pelo professor a fim de fomentar e estimular a curiosidade em seus alunos, sendo uma das possibilidades, a Sala de Aula Invertida ou Blended Learning, uma metodologia ativa, a qual o aluno realiza, em casa, algumas atividades que, normalmente, seriam realizadas na escola, e o tempo na escola seria reservado para a realização de atividades mais ativas, como experimentos, debates, atividades em grupo, pesquisas, etc. (Mattar, 2017).

Acredita-se que o seu uso possa potencializar, personalizar e facilitar a aprendizagem, tornando-a relevante, podendo contribuir para aprimorar as antigas práticas pedagógicas. $\mathrm{O}$ aluno passaria a ser protagonista no processo de aprendizagem, estimulando a colaboração entre os pares, enquanto o professor deixaria de ser mero expositor, atuando como mediador no processo.

Para Moran (2018), aprendemos desde o nascimento, a partir da relevância e significação, de processos indutivos e dedutivos. Contudo, o que traz maior significado ao aluno é a aprendizagem por experimentação e questionamento, ou seja, ativa, buscando promover uma aprendizagem que fuja da tradição bancária opressora, valorizando os conhecimentos prévios dos alunos e colocando-os em papel de destaque no processo de ensino e aprendizagem.

A aprendizagem ativa aumenta a nossa flexibilidade cognitiva, que é a capacidade de alternar e realizar diferentes tarefas, operações mentais ou objetivos e de adaptar-nos a situações inesperadas, superando modelos mentais rígidos e automatismos pouco eficientes (MORAN, $2018, \mathrm{~s} / \mathrm{n})$.

Assim, caracterizamos como metodologias ativas, práticas pedagógicas alternativas ao ensino tradicional, nas quais o aluno torna-se participativo no processo de ensino e aprendizagem, como por exemplo, resolvendo problemas e desenvolvendo projetos, a partir do que lhe é relevante.

[...] as metodologias ativas são estratégias pedagógicas para criar oportunidades de ensino nas quais os alunos passam a ter um comportamento mais ativo, envolvendo-os de modo que eles sejam 
mais engajados, realizando atividades que possam auxiliar o estabelecimento de relações com o contexto, o desenvolvimento de estratégias cognitivas e o processo de construção de conhecimento (VALENTE; ALMEIDA; GERALDINI, 2017, p. 464).

De acordo com Mattar (2017), o conceito de metodologias ativas pode ser entendido como uma educação voltada para a atividade dos alunos em contraposição à passividade, frente apenas à figura do professor detentor e transmissor do conhecimento, e esse conceito está relacionado diretamente à Internet e à sua potência na enorme disponibilização de informações. Assim, o aluno passou a assumir uma posição mais ativa no seu processo de ensino e aprendizagem e, o professor assumiu uma posição de mediador que guia e orienta.

As chamadas metodologias ativas de acordo com autores como Mattar (2017); Moran (2018), Valente, Almeida e Geraldini (2017) são: Blended Learning ou Aprendizagem Híbrida; a Sala de Aula Invertida ou Flipped Classroom; Instrução entre Pares ou Peer Instruction; Método de Caso; Aprendizagem Baseada em Problemas e Problematização; Avaliação por Pares e Autoavaliação; Design Thinking; Games, Gamificação e Simulação; Pesquisa; e Aprendizagem Baseada em Projetos.
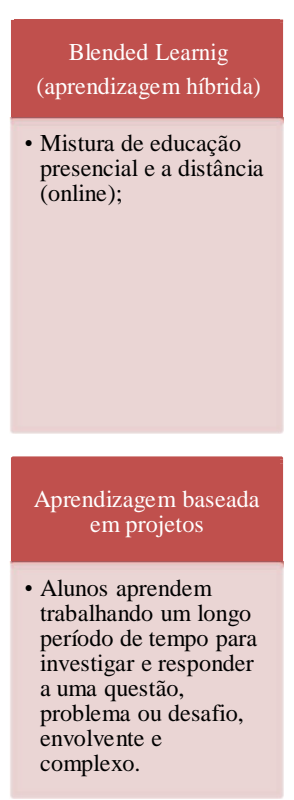

Figura 1 - Apresentação das Metodologias Ativas
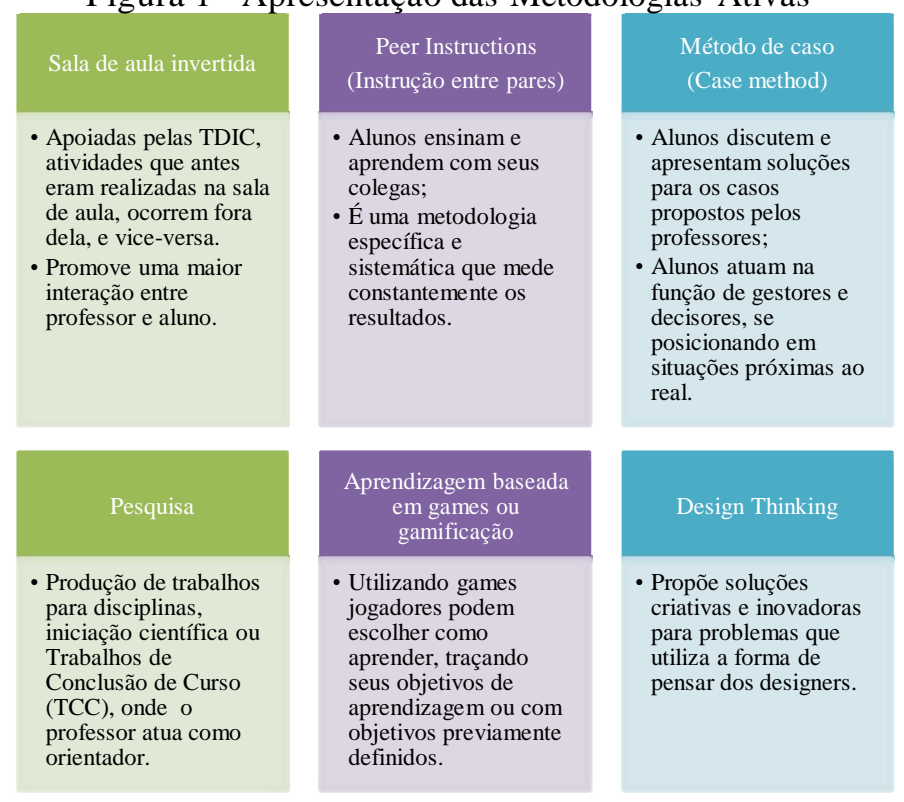
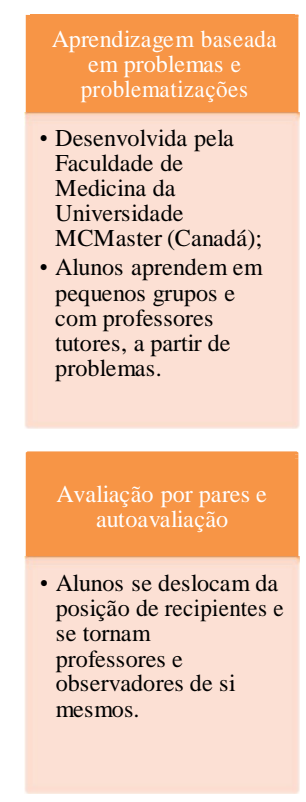

Fonte: Mattar (2017)

Para a pesquisa propusemmos a utilização da metodologia Sala de Aula Invertida. Bergmann e Sams (2018, p. 11) a caracterizam como metodologia de ensino, na qual "[...] o que tradicionalmente é feito em sala de aula, agora é executado em casa, e o que tradicionalmente é feito como trabalho de casa, agora é realizado em sala de aula". Já Moran (2018, p. 657), a define como estratégia ativa e um modelo híbrido, que otimiza o tempo em sala de aula e facilita o trabalho do professor. "O conhecimento básico fica a cargo do aluno - com curadoria do professor - e os estágios mais avançados têm interferência do professor e também um forte componente grupal".

Na Sala de Aula Invertida, a instrução direta se move do espaço de aprendizagem do grupo para o aprendizado individual, transformando a sala de aula em um ambiente dinâmico, interativo de aprendizagem, na qual o professor adota uma posição de 
mediador, orientando os alunos na aplicação de conceitos e no envolvimento criativo (FLIP LEARNING, 2014).

Ainda, de acordo com as orientações do Flip Learning (2014), também citadas por Mattar (2017), inverter uma sala de aula, não leva necessariamente a uma aprendizagem invertida, ou seja, ao aprendizado dos alunos. Para que isso ocorra, quatro pilares devem ser atendidos, como: ambiente flexível, cultura da aprendizagem, conteúdo intencional e educador profissional, ou seja, cabe ao mesmo sanar as dúvidas dos alunos, acompanhar as atividades e avaliações realizadas pelos mesmos e assim direcionar sua prática pedagógica a partir de suas necessidades (MATTAR, 2017).

Para Moran (2017), o importante ao se inverter as aulas não é utilizar tecnologias complexas, mas envolver os alunos no processo de ensino e aprendizagem, incitando questionamentos e a resolução de problemas, revendo, ampliando e aplicando o que foi apresentado no AVA, com atividades bem planejadas e feedback imediato. O professor pode começar a inversão do processo de aprendizagem realizando "[...] projetos, pesquisas, leituras prévias e produções dos alunos, e depois promover aprofundamentos em classe com a orientação do professor" (MORAN, 2017, p. 679).

De acordo com Prensky (2010), podemos dizer que os alunos de hoje, caracterizados como "nativos digitais", não aprendem da mesma forma que os das gerações anteriores. Com essa afirmação, vê-se necessário transformar também as formas de ensinar. Sendo assim, esta pesquisa buscou investigar as possibilidades e os desafios de uso da Sala de Aula Invertida na disciplina de História e responder algumas questões acerca de sua utilização na referida disciplina: É possível desenvolver uma aprendizagem colaborativa? Considerando suas atuais estruturas físicas e organizacionais, é possível implantar e desenvolver essa metodologia nas escolas públicas?

\section{MATERIAL E MÉTODOS}

A metodologia de pesquisa escolhida foi a de abordagem qualitativa, pois, conforme Bogdan e Biklen (1991), suas principais características estão no ambiente natural como fonte direta de dados do pesquisador; é descritiva; volta-se mais para o processo do que resultados ou produtos; prevê uma análise indutiva; e se pauta na perspectiva dos participantes. Assim, esta abordagem busca interpretar e dialogar com os sujeitos da pesquisa de uma forma neutra a partir de suas experiências.

Para tanto, buscamos realizar uma pesquisa bibliográfica com o objetivo de aprofundar os estudos sobre o tema em questão. "A principal vantagem da pesquisa bibliográfica reside no fato de permitir ao investigador a cobertura de uma gama de fenômenos muito mais ampla do que aquela que poderia pesquisar diretamente" (GIL, 1999, p. 65).

Por envolver uma pesquisa com alunos, o projeto foi elaborado e submetido ao Comitê de Ética da Faculdade de Ciências da UNESP de Bauru, sendo devidamente aprovado. Assim, alunos, pais e a direção foram informados sobre seus objetivos e procedimentos e orientados a ler e assinar os Termos de Assentimento ou Consentimento Livre e Esclarecido (TALE/TCLE).

A aplicação da metodologia Sala de Aula Invertida nas aulas de História ocorreu de forma articulada com as orientações do Currículo Oficial do Estado de São Paulo. Foram realizados cinco encontros presenciais, cada um com duas aulas de cinquenta minutos, junto aos alunos do $2^{\circ}$ ano do Ensino Médio, durante o segundo bimestre do ano de 2018. As aulas foram desenvolvidas a partir da situação de aprendizagem 2 "As indulgências e os protestantes" relacionada aos conteúdos e temas: "Reforma Religiosa Europeia e Contrarreforma Católica" presente no volume 1 do caderno do professor (SÃO PAULO, 2014b) e do aluno (SÃO PAULO, 2014a), realizando as adaptações necessárias, 
tendo em vista a realidade da escola e as necessidades do aluno, com o apoio das ferramentas Google ${ }^{\circledR}$ Sala de Aula e Whatsapp.

Após a aplicação da metodologia, foi realizada entrevista junto aos alunos participantes com o objetivo de analisar os desafios e as contribuições da prática metodológica em seu aprendizado, na suplementação ou enriquecimento dos conteúdos escolares, na colaboração entre os pares, no protagonismo discente e na potencialização de suas habilidades. Em seguida, os dados foram analisados qualitativamente e os resultados apresentados.

\section{RESULTADOS E DISCUSSÕES}

Nesta pesquisa, destacamos que a Sala de Aula Invertida foi entendida como uma metodologia na qual os alunos estudavam o conteúdo em casa, disponibilizado pelo professor em um Ambiente Virtual de Aprendizagem (AVA), tomando como base os estudos de Mattar (2017) e Moran (2018), não só a partir de vídeos, mas também leituras prévias, chats, fóruns, questionários, slides, áudios, jogos, pesquisas, bem como outras estratégias que o professor pesquisador julgou pertinentes e adequadas para cada situação de aprendizagem. Assim, a Sala de Aula Invertida, no AVA, envolveu atividades individuais e em grupo, proporcionando um aprendizado colaborativo também online.

A pesquisa foi realizada com uma turma do $2^{\circ}$ ano do Ensino Médio de uma Escola Estadual localizada no município de Bauru, Estado de São Paulo, em uma região periférica com graves problemas de vulnerabilidade social, infraestrutura e saneamento básico, enfrentando também o forte tráfico de drogas que acomete parte dos estudantes, o alcoolismo e a violência. Participaram da pesquisa 17 alunos, sendo 9 do gênero masculino e 8 do feminino, com idade entre 16 e 18 anos. 3 deles encontram-se em defasagem ano/série.

A unidade escolar iniciou suas atividades no ano de 2015, o prédio foi entregue inacabado, com problemas estruturais e com falta de recursos materiais e pedagógicos, situação que, em parte, ainda permanece. O laboratório de informática, que iniciou suas atividades somente três anos depois da inauguração da unidade, possui, hoje, 18 computadores, 8 foram doados por uma escola privada da grande São Paulo e apenas 14 estão em bom estado de funcionamento.

É considerável o número de alunos que necessitam de encaminhamento pedagógico para recuperação contínua, em destaque, na deficiência das competências leitora, escritora e raciocínio lógico matemático envolvendo as quatro operações básicas; existem problemas de evasão e frequência; dificuldades em realizar um trabalho coletivo entre professores e alunos; a integração escola x comunidade precisa ser aperfeiçoada; casos de vandalismos, carência de materiais pedagógicos e problemas estruturais prejudicam o processo de ensino e aprendizagem.

Nesse sentido, esta pesquisa buscou aplicar a metodologia Sala de Aula Invertida nas Aulas de História e analisar os desafios e as potencialidades da mesma como possibilidade para o processo de ensino e aprendizagem e a aprendizagem colaborativa.

É importante destacar que os alunos participantes da pesquisa nunca haviam entrado em contato com a metodologia da sala de aula invertida e que, desde a inauguração da escola, há quatro anos, não tinham contato com a sala de informática, pois a mesma não existia na unidade. Sendo assim, inauguramos a sala com a pesquisa, tudo era novidade para os alunos que demonstraram ansiedade e euforia. Tendo em vista o cenário apresentado, ou seja, como se tratava de uma primeira aproximação dos alunos com a metodologia, para sua realização, foram planejadas atividades envolvendo a análise prévia de vídeos, pesquisas individuais e em grupo e debates, intencionando uma aprendizagem colaborativa e o desenvolvimento de sua autonomia. 
As impressões dos participantes foram coletadas a partir da realização de entrevista com um grupo de oito alunos e a aplicação de questionário final estruturado a partir de questões fechadas sobre as videoaulas utilizadas, bem como as atividades disponibilizadas no Google Sala de Aula e possíveis dificuldades técnicas para sua utilização.

No questionário, sobre as videoaulas perguntamos: Houve clareza na explicação dos conteúdos? Você compreendeu o conteúdo assistindo as videoaulas? Para ambas as perguntas, as respostas foram de $62,5 \%$ para sim, $25 \%$ parcialmente e $12,5 \%$ informaram que não assistiram ao vídeo.

Apesar de apenas um aluno (12,5\%) ter respondido que não assistiu ao vídeo, é importante esclarecer que, na aula da terceira semana, a turma deveria ter assistido ao mesmo como atividade invertida (em casa), contudo, no início da aula, os alunos foram questionados sobre a realização da atividade, e cerca de 50\% informaram não ter assistido. Perguntamos o motivo, e muitos disseram que tiveram dificuldades técnicas em acessar a ferramenta Google Sala de Aula pelo celular $(37,5 \%)$, no qual o login informado é o RA do aluno, composto por cerca de 13 números + dígito + SP@al.educacao.sp.gov.br, o que acabou confundindo muitos deles.

Essas dificuldades foram constatadas já na primeira semana de realização da pesquisa, na qual os alunos puderam ter contato e se familiarizar com a ferramenta, outros alunos também entenderam que poderiam acessar a ferramenta com o login pessoal do Google. Sanadas as dúvidas, disponibilizamos a senha do wi-fi da escola para a turma nos últimos 15 minutos da aula, esperando que todos pudessem baixar o App no celular e realizar o login com a ajuda da professora, mas, não foi possível finalizar com todos, pois o sinal da internet estava fraco. O que nos leva a refletir sobre um dos aspectos defendidos por Mattar (2017): para que haja o sucesso na realização da metodologia, é importante que as instituições de ensino possibilitem acesso aos equipamentos e conexão com a internet para que os alunos realizem as atividades.

Diante do ocorrido, para que não houvesse comprometimento na aprendizagem dos alunos, apresentamos o vídeo no início da aula e combinamos que continuaríamos realizando as comunicações também via WhatsApp com o grupo já criado, mesmo assim, alguns alunos foram prejudicados, pois não possuíam o dispositivo móvel e/ou computador pessoal ou acesso à Internet em casa, lembrando que a sala de informática foi disponibilizada no contra turno para os alunos envolvidos na pesquisa, no entanto, não houve procura. Na tentativa de atender a todos os alunos, foi oferecida também a entrega das atividades de forma escrita no caderno, utilizando outras formas de pesquisa.

A situação relatada acima nos encaminha as informações fornecidas pelo CETIC.br (2018), no qual $27 \%$ dos brasileiros entrevistados informaram não possuir acesso à Internet devido ao preço elevado do serviço, sendo que o acesso via dispositivo móvel continua sendo o mais utilizado pelas classes D/E. Informação que vai ao encontro com os dados aqui levantados e a necessidade de implementação de políticas públicas que promovam o acesso igualitário da população ao universo virtual.

Constata-se que as atividades da terceira semana desempenhadas em sala de aula ocorreram de forma satisfatória. Os alunos se organizaram em grupos produtivos e com o auxílio de um computador, realizaram as atividades propostas. Apresentamos abaixo um trecho da entrevista ${ }^{1}$ realizada e as impressões dos alunos sobre essa atividade.

\footnotetext{
${ }^{1}$ Fala da Pesquisadora representada pela letra "P" e dos alunos pelas letras "A1, A2, A3, A4 e A5".
} 


\begin{abstract}
P- Na aula da terceira semana vocês se organizaram em grupo com um computador e diversas questões para pesquisa. Quais são as impressões de vocês sobre essa atividade? A1- Foi boa, pois um ajudou o outro, mas em algumas situações fica difícil, porque alguns alunos são bagunceiros e não querem fazer as atividades.

P-Se nós continuássemos com esse tipo de organização da sala vocês acham que esses alunos bagunceiros poderiam se interessar mais? A1Eu acho que sim, porque, dependendo do conteúdo, eles se interessam, e quebrar a rotina de cada um sentando atrás do outro iria melhorar as aulas. A2- Foi melhor, porque podemos tirar dúvidas entre nós. A aula que foi melhor aproveitada foi em grupo. A3- Nós entendemos, porque nós conversamos entre nós e escrevemos o que achamos mais importante. A4- Mais ou menos. Porque algumas pessoas não estavam interessadas e tinha muita conversa, eu aprendo melhor sozinho, pois só depende de mim, mas foi bom, as aulas ficaram mais dinâmicas e mais fáceis de entender. [...] Depende do que vai fazer, se for uma atividade que precisa de concentração é melhor em fila.
\end{abstract}

Apesar do aluno A4 indicar sua preferência na realização de atividades individuais, ficou claro, entre os demais alunos, as possibilidades e benefícios da colaboração entre os pares. Podemos constatar que nas atividades realizadas na segunda semana, nas quais os alunos fizeram um levantamento das religiões seguidas pela comunidade escolar, e nas atividades em grupo da terceira semana, ocorreu envolvimento intenso. Entendemos que, com essas atividades, colocamos o aluno no centro do processo de ensino e aprendizagem. O professor, nas duas atividades planejadas, adotou a postura de mediador. Acreditamos ser esse um dos caminhos para que possamos desenvolver a autonomia e o protagonismo junto aos alunos.

[...] como inclusão da metodologia da Sala de Aula Invertida, [...] o professor permite que os próprios alunos resolvam e apresentem suas atividades, em grupo, para os demais colegas, permitindo, assim, que expressem suas diversas formas e técnicas de resolução, bem como promove a interação entre os alunos, permitindo o ensino de forma colaborativa (ALMEIDA, p. 44, 2017).

Sobre a ferramenta Google Sala de Aula, fizemos as seguintes perguntas: Você realizou todas as atividades propostas pelo professor? $87,5 \%$ dos alunos responderam que realizaram parcialmente e $12,5 \%$ que sim. Você teve dificuldade em realizar as atividades? $87,5 \%$ responderam que não e $12,5 \%$, um pouco. Houve clareza nos feedbacks do professor? 62,5\% responderam que sim, $12,5 \%$, não e $25 \%$, parcialmente.

Os resultados apresentados nos encaminharam para a entrega da atividade invertida solicitada aos alunos na quarta semana pela ferramenta Google Sala de Aula e também via WhatsApp. É importante esclarecer que apenas duas foram entregues via Google Sala de Aula, sendo uma delas fora do prazo. O que nos apontou para a necessidade de realizar um trabalho intenso, prévio e contínuo de conscientização junto aos alunos sobre a importância da realização das atividades e do estudo em casa, não somente para que a metodologia alcance os resultados esperados, mas que haja sucesso e qualidade na aprendizagem, independente da metodologia utilizada pelo professor. É importante que o aluno compreenda que também é responsável pela sua aprendizagem (MATTAR, 2017). 
A preparação é necessária para que os alunos compreendam alguns conceitos relacionados à aprendizagem colaborativa e aos elementos de colaboração, conheçam a proposta da metodologia sala de aula invertida e também para que se familiarizem com o Ambiente Virtual de Aprendizagem, aprendendo como utilizar suas ferramentas e funcionalidades (HONÓRIO, 2017, p. 44).

Como a atividade da quarta semana se tratava de uma pesquisa sobre Martinho Lutero, o Padre Beto da cidade de Bauru-SP e os motivos que levaram à excomunhão, nos primeiros dez minutos da aula realizamos uma breve apresentação dos resultados com o auxílio dos alunos que haviam realizado a pesquisa em casa, no caso, apenas dois. Em seguida, nos encaminhamos para as atividades planejadas: pesquisa em duplas, sobre as origens históricas dos conflitos entre católicos e protestantes na Irlanda do Norte. Constatamos que nessa aula não ocorreu conforme o esperado, os alunos, mesmo após orientações da professora sobre os caminhos para uma boa pesquisa, realizaram o chamado "copia e cola" das respostas para o Google Sala de Aula. Ao final nos organizamos em semicírculo e socializamos os resultados. Foi necessária intervenção maior da professora diante do ocorrido. Na entrevista, questionamos a postura dos alunos diante da atividade e foi interessante identificar que eles se colocaram conscientes do resultado de suas ações diante de sua aprendizagem.

P- Quando vocês fizeram a pesquisa da quarta semana vocês realmente leram o que estavam pesquisando? A4- Eu li a primeira linha e como vi que estava dando sentido eu copiei e colei.

P- Vocês aprenderam? A4- Não. A3- Não li, pesquisamos copiamos e colamos.

P- Faltou orientação da professora? A3- Não.

P-E porque copiaram e colaram? A3- Porque era mais fácil.

P- Mas vocês entenderam o que pesquisaram? A3- Só depois que a professora explicou.

"Ao restringir-se a um pequeno espaço da rede, ao fazer leituras superficiais e ao ignorar todo o vasto conteúdo presente na internet, corre-se o risco de formar um sujeito autônomo falseado e superficial" (GROSSY, GONÇALVES e TIFY, 2014, p. 651). Ainda, de acordo com os autores, diante dessa sociedade da informação, um dos desafios do professor é possibilitar ao aluno o desenvolvimento de habilidades para que possa aprender a selecionar as diversas informações disponíveis na Internet e outras mídias, imprimindo nelas um significado, possibilitando o desenvolvimento de uma postura crítica e cidadã, que desenvolvam o chamado "letramento informacional", ou seja, a competência de tratar qualitativamente a informação diante da sociedade tecnológica na qual estamos inseridos.

O fato apresentado vem fortalecer as discussões sobre a necessidade de uma sólida formação inicial e continuada do professor, não só para o uso das TDIC na prática pedagógica, mas também para a utilização de novas metodologias ativas, diante dos atuais alunos e da sociedade na qual estamos inseridos. Um exemplo disso surgiu nas entrevistas com três alunos.

P- Como as aulas têm acontecido no dia a dia? A3- É normal.

P- O que é normal? A3- Cada um na sua carteira fazendo o seu.

P- Sobre as atividades realizadas na escola, quais foram as suas impressões? A1- Foram atividades diferentes, as únicas diferentes para falar a verdade. Nós sentamos em roda, conversamos sobre o assunto, 
depois sentamos em grupo e depois os grupos falaram o que acharam da atividade.

P- Vocês costumam sentar em roda nas outras disciplinas? A1 - Só na disciplina de Sociologia e de História.

P- E como é o aproveitamento das aulas? A1- O aproveitamento das aulas é bom, conseguimos trocar ideias e conversar mais. A5- Mas sentar muito em roda também cansa, porque a gente fica falando, falando e falando aí cansa, o bom é variar com aulas mais práticas.

A avaliação da aprendizagem ocorreu de forma contínua e sistemática, sendo a última atividade, a proposta de um Quiz organizado na ferramenta Kahoot com questões sobre os conteúdos estudados. Como estávamos na última semana de aula antes do período de férias, poucos alunos participaram dessa atividade. Porém, os que participaram, obtiveram bom aproveitamento nas respostas. Encaminhamos-nos, então, para as impressões dos alunos na entrevista sobre a metodologia Sala de Aula Invertida.

P- Quais foram as suas impressões sobre a metodologia sala de aula invertida? A1- Ela é boa, mas a maioria esquece de fazer, como estamos em casa é mais fácil de ver e entender o vídeo. Aproveitamos mais o tempo na sala de aula, pois já estudamos antes o conteúdo com o vídeo. P- Você sentiu falta da explicação do professor em sala de aula? A1Não, nem tanto, porque as coisas que eu não tinha entendido eu poderia pesquisar em casa. A2- Foi interessante porque a professora não ficava falando, falando, falando, dependia também de você e do que você trazia de casa. A3- Funciona, mas não com todos os alunos, porque nem todos estão interessados. Na escola alguns alunos só fazem a atividade porque ganha visto e ponto, mas em casa ninguém está vendo se você fez ou não fez. Mas eu achei muito interessante o assunto, tanto que eu assisti aos dois vídeos, e eu acho que está faltando isso pra gente, estudar mais em casa. A4- A metodologia ajuda se a pessoa se interessar. Porque não precisa ficar falando a mesma coisa na sala, mas em casa dá preguiça, na escola a gente vem pra estudar. A5- O professor fala menos, e às vezes isso é bom porque cansa menos e a gente aproveita mais porque as aulas são mais práticas e quando nos organizamos em grupo a gente conversa mais.

Os resultados apresentados nos encaminharam para as reflexões de Knuth (2016, p. 39), nas quais o objetivo da metodologia é unir o virtual e o presencial, utilizando as TDIC no processo, visando otimizar o tempo em sala de aula, possibilitando um espaço de interação, participação e colaboração entre os alunos e professores, "trocando ideias, buscando conhecimentos, interagindo e colaborando com os demais e, ao mesmo tempo, recebendo ajuda de todos os que estão na rede de amigos e na internet".

\section{CONSIDERAÇÕES FINAIS}

Buscamos apresentar neste recorte de uma pesquisa mais abrangente, avaliar os desafios e as potencialidades da utilização da metodologia Sala de Aula Invertida no processo de ensinar e aprender na disciplina de História e responder algumas questões acerca de sua utilização na referida disciplina: É possível desenvolver uma aprendizagem colaborativa? Considerando suas atuais estruturas físicas e organizacionais, é possível implantar e desenvolver essa metodologia nas escolas públicas?

A partir dos resultados das entrevistas com os alunos, foi possível compreender que a utilização da metodologia possibilitou uma aprendizagem relevante e colaborativa. A fala dos educandos demonstrou que as aulas, nas quais foram utilizadas a metodologia 
com o apoio das TDIC, se tornaram mais dinâmicas e interessantes, pois a troca de ideias contribuiu para o aprendizado.

Com isso, ficou claro que os alunos almejam uma mudança, inclusive, estrutural da escola, fato que pode ser observado nos comentários sobre a organização da sala de aula.

Acreditamos que a utilização de diversas metodologias ativas, além de oportunizar um aprendizado relevante aos alunos diante dos conteúdos historicamente construídos, pode também contribuir com o desenvolvimento da colaboração, autonomia e protagonismo, habilidades imprescindíveis diante dos desafios e exigências da sociedade do século XXI, na qual se espera que as instituições escolares promovam uma educação integral, que rompa com a fragmentação disciplinar e prepare o aluno para a resolução de problemas e o gerenciamento da própria aprendizagem.

Portanto, alguns desafios devem ser superados para que a metodologia possa alcançar bons resultados, como a conscientização dos alunos na importância da realização de todas as atividades propostas (virtual e presencial) e o desenvolvimento do letramento informacional.

Mas, além disso, é urgente a promoção de políticas públicas que invistam na formação continuada de professores para o uso das TDIC e a valorização do trabalho docente, possibilitando mais tempo para que o mesmo possa organizar e planejar suas aulas e interagir com seus pares. Assim, a escola pode se tornar geradora, gestora e não só consumidora e transmissora do conhecimento, alimentando a cultura, o diálogo, a solidariedade e a convivência com a diferença e a democracia.

\section{REFERÊNCIAS}

ALMEIDA, B. L. C. Possibilidades e limites de uma intervenção pedagógica pautada na metodologia da sala de aula invertida para os anos finais do ensino fundamental. 2017. 137 f. Dissertação (Mestrado Profissional em Matemática em Rede Nacional)Universidade Tecnológica Federal do Paraná, Pato Branco, 2017.

ALMEIDA, M. E. B. de; VALENTE, J. A. Políticas de Tecnologia na Educação Brasileira: histórico, lições aprendidas e recomendações, 2016. Disponível em: <http://www.cieb.net.br/wp-content/uploads/2016/12/CIEB-Estudos-4-Politicas-deTecnologia-na-Educacao-Brasileira.pdf >. Acesso em: 27 jan. 2018.

BERGMANN, J; SAMS, A. Sala de Aula Invertida: uma metodologia ativa de aprendizagem. Tradução de Afonso Celso da Cunha Serra. 1. ed. Rio de Janeiro: LTC, 2018. Versão digital e-book adquirido na Amazon/Kindle.

BOGDAN, R; BIKLEN, S. Investigação qualitativa em educação: uma introdução à teoria e aos métodos. 10 ed. Porto Editora, 1991.

CETIC.BR. Acesso à Internet por banda larga volta a crescer nos domicílios brasileiros Disponível em: <https://www.cetic.br/noticia/acesso-a-internet-por-bandalarga-volta-a-crescer-nos-domicilios-brasileiros/>. Acesso em: 11 out. 2018.

FLIP LEARNING. What Is Flipped Learning? Disponível em:

$<$ https://flippedlearning.org/wpcontent/uploads/2016/07/FLIP_handout_FNL_Web.pdf>. Acesso em: 20 jan. 2018.

GIL, A. C. Métodos e Técnicas de Pesquisa Social. 2 ed. São Paulo: Atlas. 1999. 
GROSSI, M. G. R.; GONÇALVES, C. F.;TUFY, S. P. Um panorama das tecnologias digitais da informação e comunicação na educação: desafios, habilidades e incentivos estatais. Perspectiva, Florianópolis, v. 32, n. 2, p. 645-665, maio/ago. 2014.

HONORIO, H. L. G. Sala de Aula Invertida: uma abordagem colaborativa na aprendizagem de matemática. 2017. 96 f. Dissertação (Mestrado Profissional em Educação Matemática) - Universidade Federal de Juiz De Fora, Juiz de Fora, 2017.

KNUTH, L. R. Possibilidades no ensino de Geografia: o uso de tecnologias educacionais digitais. 2016. 207 f. Dissertação (Mestrado em Geografia) - Universidade Federal de Pelotas, Pelotas, 2016.

MATTAR, J. Metodologias Ativas: para a educação presencial, blended e a distância. 1 ed. São Paulo: Artesanato Educacional, 2017.

MORAN, J. Metodologias ativas para uma aprendizagem mais profunda. In: BACICH, L.; MORAN, J. (Org.). Metodologias ativas para uma educação inovadora: uma abordagem teórico-prática. Porto Alegre: Penso, 2018. Não paginada. Versão digital ebook adquirido na Amazon/Kindle.

PALFREY, J; GASSER, U. Nascidos na Era Digital: entendendo a primeira geração de nativos digitais. Porto Alegre: Grupo A, 2011.

PRENSKY, M. "Não me atrapalhe, mãe - estou aprendendo!": Como os videogames estão preparando nossos filhos para o sucesso no século XXI - e como você pode ajudar! São Paulo: Editora Phorte, 2010.

. Secretaria da Educação. Caderno do aluno: História, Ensino Médio - $2^{\circ}$ ano, volume 1. São Paulo: SE, 2014a.

. Secretaria da Educação. Caderno do professor: História, Ensino Médio - $2^{\circ}$ ano, volume 1. São Paulo: SE, 2014b.

TEZANI, T. C. R. A educação escolar no contexto das Tecnologias da Informação e da Comunicação (TIC): desafios e possibilidades para a prática pedagógica curricular. Revista Faac, v. 1, n. 1, p. 36-45, 2011.

VALENTE, V. A.; ALMEIDA, M. E. B.; GERALDINI, A. F. S. Metodologias ativas: das concepções às práticas em distintos níveis de ensino. Rev. Diálogo Educ., Curitiba, v. 17, n. 52, p. 455-478, abr./jun. 2017. 